domain $30^{\circ}-55^{\circ} \mathrm{N}, 75^{\circ}-130^{\circ} \mathrm{W}$, for a period covering 1850-1980 AD ( $n=13$, using the infilled instrumental data set of Mann et al. 2009). Finally, this calibration fit was used to reconstruct decadal averages of annual temperature over the larger domain for the entire 1200-1980 AD period ( $n=78$ ). In both regressions, the fitted values were scaled so that their variance matched that of the target data during the fitting period. The results are shown in Figure 1; the red (blue) curves give the full (western) North American expected value (EV) reconstructions, and the black curve shows the 18502000 AD full North American instrumental values.

Uncertainty estimation was done using the uncertainty ensembles generated for both the WS12 and the 1200-on reconstructions (see Wahl and Smerdon 2012 for the statistical bootstrap method used) in a two-way Monte Carlo design. In this design, the process described above to estimate the EV reconstructions was repeated for each possible combination of 500 WS12 and 500 1200-on ensemble members. The $99 \%$ probability range estimated by this analysis (from the 0.005 and 0.995 quantiles of the MC output) is shown by the thin solid red line in Figure 1. Note that these $99 \%$ ranges are for the decadal means and thus are significantly narrower than the corresponding ranges for annual values would be expected to be, from theory of the standard error of the mean.

Several side-by-side comparisons of the tree-ring derived reconstruction with observations were done to investigate its ability to reproduce the large-scale patterns of change on decadal and multidecadal time scales. The comparisons (not shown) indicate that the western North America-based reconstruction captures the primary features of temporal variability during the instrumental period, along with many sub-regional spatial features such as warming in the interior Southwest associated with the 1950s drought, and also likely captures decadal variability over the larger continental region east to $75^{\circ} \mathrm{W}$. Additionally, the reconstruction was compared against lake-sediment pollen temperature reconstructions for the Upper Midwest and eastern portion of the mid-North American continent (Wahl et al. 2012; Viau et al. 2012; Trouet et al., this issue). We find general agreement between the results shown here and the bulk of the regional temperature reconstructions reported in these pollen-based studies.

There have been relatively few reconstruction studies of long-term North American temperature compared to precipitation or related drought indices (e.g. Cook et al. 1999, 2007). We single out two recent articles (Kaufman et al. 2009; Ljunqvist et al. 2012) that present millennial length reconstructions for portions of the Northern Hemisphere, since they include some information regarding North American temperature changes. A direct comparison between these reconstructions and that of Figure 1 is not possible however, because of differing reference periods and data sources on the one hand (Ljunqvist et al. 2012) and a pan-Arctic regional focus on the other (Kaufmann et al. 2009). Nevertheless, some similarities are evident, particularly the cold periods of the $17^{\text {th }}$ and $19^{\text {th }}$ centuries, and warmer temperatures prevailing prior to the $15^{\text {th }}$ century.

\section{Selected references}

Full reference list online under:

http://www.pages-igbp.org/products/newsletters/ref2012_2.pdf

Kaufmann DS et al. (2009) Science 325: 1236-1239

Ljunqvist FC, Krusic PJ, Brattström G, Sundqvist HS (2012) Climate of the Past 8: 227-249

Viau AE, Ladd M, Gajewski K (2012) Global and Planetary Change 84-85: 75-83

Wahl EW, Diaz HF, Ohlwein C (2012) Global and Planetary Change 84-85: $66-74$

Wahl ER, Smerdon JE (2012) Geophysical Research Letters 39, doi: 10.1029/2012GLL51086

\title{
A pollen-based extension of the 800-year decadal- scale reconstruction of annual mean temperature for temperate North America dating back to 480 AD
}

\author{
Valerie Trouet ${ }^{1}$, H.F. Diaz ${ }^{2}$, A.E. Viau ${ }^{3}$, E.R. Wahl ${ }^{4}$ \\ 'Laboratory of Tree-Ring Research, University of Arizona, Tucson, USA; trouet@email.arizona.edu \\ ${ }^{2}$ Cooperative Institute for Research in Environmental Sciences, University of Colorado, Boulder, USA; ${ }^{3}$ Department of Geography, University of \\ Ottawa, Canada; ${ }^{4}$ National Climatic Data Center, National Oceanic and Atmospheric Administration, Boulder, USA
}

\section{We present a tree-ring and pollen based mean annual temperature reconstruction for temperate North America (480-1980 AD) that shows two prominent low-frequency periods: the warmer Medieval Climate Anomaly (750- 1100 AD) and the cooler Little Ice Age (1300-1850 AD).}

\begin{abstract}
$T_{\text {to }}^{\text {he }}$ he PAGES 2k Network initiative aims to reconstruct climate variables for the last 2000 years. In a parallel effort, the NAM2K group produced an 800year (1200-1980 AD) decadal scale annual mean temperature reconstruction using a network of tree-ring records in western North America (Wahl et al. 2012a, this issue; Wahl and Smerdon 2012). That reconstruction is referred to henceforth as D1200 (for decadal 1200). Here we present a pollen-based 30-year
\end{abstract}

resolution mean annual temperature reconstruction for the temperate region of North America $\left(30^{\circ}-55^{\circ} \mathrm{N}, 95^{\circ}-130^{\circ} \mathrm{W}\right)$ extending D1200 back to $480 \mathrm{AD}$. In the following, we describe the methodology used for this reconstruction and briefly compare it with other regional temperature reconstructions.

We performed a principal component analysis (PCA) using four North American regional pollen-based temperature reconstructions (Viau et al.
2012); specifically those based on pollen sequences from deciduous, hardwood, boreal, and mountain ecoregions of North America. The prairie ecoregion reconstruction for the center of Northern America was not used as its vegetation is mainly controlled by precipitation (Viau et al. 2012). Mean annual temperature reconstructions were used instead of summer temperature anomalies as in Viau et al. (2012) for a more direct comparison of the pollen reconstructions to 
D1200. The resulting 30-year PCA scores (360-1950 AD; $n=54$ ) were then included in a stepwise multiple linear regression against the D1200 curve. For this purpose, D1200 was smoothed using a $~ 110$ year lowess filter and sampled every 30 years to conform with the time scale and sampling resolution of the pollenbased reconstructions. Three combined PC axes explaining $87 \%$ of the common variance in the pollen reconstructions were retained in the stepwise regression and explained $33.4 \%$ of the variance (corrected for autocorrelation) in D1200.

Uncertainty was estimated based on the 1 and 2 standard error (SE) limits for the pollen-based reconstructions and the SE of the regression model. The SEs for the pollen-based reconstructions were developed using a Monte Carlo resampling technique that generated random sequences by sampling values at each time step of the individual pollen series within each series' uncertainty limits. This process was repeated 10,000 times to generate the pollen-based reconstruction uncertainty bands. These were then inputted into the previously developed PCA and multiple linear regression equations to determine the component of the overall 1SE and 2SE uncertainty limits that is inherent in the pollen-based reconstruction method. The pollen-based reconstruction 1SE and 2SE limits estimated in this manner were augmented with the corresponding regression 1 SE and 2 SE values at each time step, by adding the squares of the errors and taking the square root of the sum. Because estimated uncertainties were unrealistically high prior to $480 \mathrm{AD}$, we truncated our temperature reconstruction at this date.

Comparison between D1200 and the pollen reconstruction is quite reasonable (Fig. 1). Except for a peak around $1300 \mathrm{AD}$, the smoothed D1200 falls nearly entirely within the 1 SE uncertainty envelope. The overall amplitude of change for the entire period is $\sim \pm 0.55^{\circ} \mathrm{C}$ and thus falls within the range of amplitudes found for hemispheric-scale temperature reconstructions over the last millennium $\left(0.4-1{ }^{\circ} \mathrm{C}\right.$, see Esper et al. 2012). The start date of our reconstruction is too recent to capture warmth during Roman times (0-400 AD) and this is likely one of the reasons why a millennium-scale cooling trend, caused by orbital forcing, is not as evident as in high-latitude temperature reconstructions for the same period (Kaufman et al. 2009; Esper et al. 2012).

There are three prominent low-frequency periods in the North American extended reconstruction, notably the cooler Dark Ages (ca. 500-700 AD), Little Ice Age (ca. 1300-1850 AD), and warmer Medieval Climate Anomaly (MCA; see also Wahl et al. 2012b). Our results show that the MCA, here between ca. 750 and $1100 A D$, was slightly warmer than the baseline period (1904-1980 AD), but much cooler than the early 21 st century (Fig. 1). The MCA shows peaks around 850 and 1050 AD. Following the MCA, mean annual temperatures decreased until the mid-19 $9^{\text {th }}$ century, after which temperature began to increase rapidly. Our reconstruction shows similarities with other long temperature reconstructions, not only at the centennial scale (e.g. cold Dark Ages in Büntgen et al. 2011), but also at the decadal scale. Warmth in the mid- $11^{\text {th }}$ century and cool $17^{\text {th }}$ and $19^{\text {th }}$ centuries, in particular, are well replicated in multiple hemispheric-scale temperature reconstructions (e.g. Frank et al. 2010; Mann et al. 2009; Moberg et al. 2005).

\section{Selected references}

Full reference list online under:

http://www.pages-igbp.org/products/newsletters/ref2012_2.pdf

Esper J et al. (2012) Nature Climate Change, doi: doi:10.1038/nclimate 1589

Kaufman DS et al. (2009) Science 325: 1236-1239

Viau AE, Ladd M, Gajewski K (2012) Global and Planetary Change 84-85: 75-83

Wahl EW, Diaz HF, TrouetV, Cook ER (2012a) PAGES News 20(2): xx-Xx

Wahl ER, Smerdon JE (2012) Geophysical Research Letters 39, doi: $10.1029 / 2012 G L 051086$

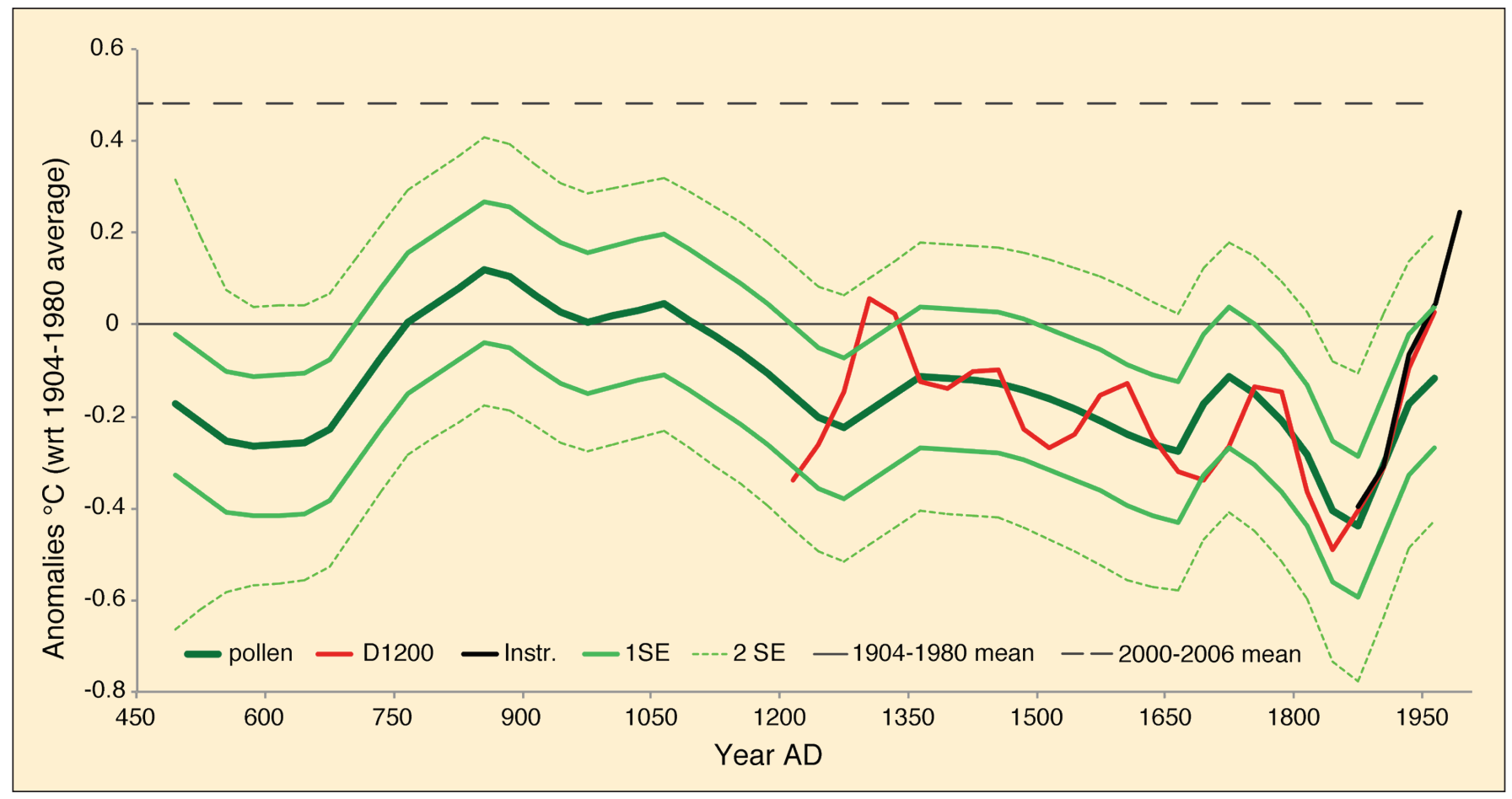

Figure 1: Reconstruction (dark green curve) of 30-year averages of annual mean temperature deviations from a $1904-1980 \mathrm{AD}$ average for North America ( $30^{\circ}$-55 $\mathrm{N}$, $75^{\circ}$ $130^{\circ} \mathrm{W}$ ). Values shown correspond to the combination of three pollen-reconstruction PC s resulting from a stepwise multiple linear regression with the 30 -year-subsampled $R C$ temperature series (red curve), and thus reflects low frequency variations. Dashed (full) light green lines give 2SE (1SE) uncertainty estimations associated with each 30-year value. Full black curve shows comparably smoothed instrumental temperature values. Dotted black line represents the average deviation for the period $2000-2006$ AD, also from comparably smoothed instrumental data. 